This is an Open Access article, distributed under the terms of the Creative Commons Attribution licence (http://creativecommons.org/licenses/by/4.o/), which permits unrestricted re-use, distribution, and reproduction in any medium, provided the original work is properly cited.

doi:10.1017/So1 44686X17001507

\title{
Non-kin ties as a source of support amongst older adults 'left behind' in Poland: a quantitative study on the role of geographic distance
}

\author{
NINA CONKOVA* and RUSSELL KING ${ }^{\dagger}$
}

\begin{abstract}
In the transition to democracy and a market economy, the Central and Eastern European countries experienced rapid and fundamental changes. Large-scale emigration flows and pronounced reductions in previously universal welfare systems increased the phenomenon of 'left behind' older adults. We examine this phenomenon in the case of Poland, a rather family-oriented society which in recent years sent most emigrants to Western Europe in absolute terms. Employing a support system framework and representative survey data, we enquire into older adults' support patterns. Our results suggest that older adults in Poland rely predominantly on family support, although this varies greatly across living arrangements. We also find a positive association between distance separating parents and their closest child, and support from at least one non-kin. Yet, our findings reveal differences between practical and emotional support, with the latter being more likely to be provided by non-kin, but with distance mattering to a lesser degree. Parents with very distant child(ren) are few and differ only from parents with very proximate child(ren), a finding prompting the question as to what is the difference between being 'left behind' by international and by internal migration. We conclude that the phenomenon of 'left behind' in Poland, at least in terms of support, is less a matter of children's migration and more an issue of household and regional context.
\end{abstract}

KEY WORDS - migration, social support, non-kin ties, left behind, Poland, quantitative analysis.

* Department of Public Administration and Sociology, Erasmus University Rotterdam, The Netherlands.

$\dagger$ Sussex Centre for Migration Research, University of Sussex, Brighton, UK. 


\section{Introduction}

The expansion of the European Union (EU), along with the process of globalisation, has brought about an increasing number of mobile people who move within, into and out of the European continent for a variety of reasons, but most often related to work and income. This movement of people has in turn led to changes in family life in its various aspects. Families that are subjected to the experience of migration - either directly or indirectly - are faced with multiple new situations, many of which might entail reduced emotional closeness and fewer possibilities for support between family members (Zhou 2012). As a result, within the broad and diverse research field of migration studies, a sub-literature has emerged on those 'left behind' by migration, who typically fall into three categories - migrants' spouses, migrants' children and migrants' parents. In this contribution, we bring to the forefront migrants' parents 'left behind' in Poland and their support systems - a network of people who provide an individual with practical and emotional support.

The literature on the left-behind parents of migrants consists mainly of studies from China and other parts of Asia, most of which focus on internal migration (see e.g. Biao 2007; He and Ye 2014; Knodel and Saengtienchai 2007). Another important study to note, set within the optic of long-distance transnational care, is Baldassar's pioneering research on Italian migrants in Australia and their old-age parents in Italy (Baldassar 2007; Baldassar, Baldock and Wilding 2007). Thus far, research on parents left behind by migration within Europe has been scarce and mostly small scale. Exceptions have been Gedvilaitė-Kordušienè (2015) on Lithuania; King and Vullnetari (2006) on Albania; Krzyzowski and Mucha (2014) on Poland; Waidler et al. (2016) on Moldova; and Zimmer, Rada and Stoica (2014) on Romania. These latter studies reflect the recency of large-scale East-West migration flows, consequent on EU enlargements in 2004 and 2007, and hence the relative newness of the phenomenon of the 'left behind' in Europe (Black et al. 2010; Favell 2008).

In some of the former communist countries, such as Poland, emigration has become such an important part of life that the emergence of a 'culture of emigration', in which working abroad is a normal rite de passage for young people, has been noted (Cieślińska 2012: $5^{8)}$ ). This emigration of young people is accompanied by high levels of familialism and varying degrees of rapid institutional change, leaving many older parents not only without one of the most important sources of support - their child(ren) - but also without meaningful state support. Given that Poland is the country which, in absolute terms, has been sending most migrants to the West, we select it as a case study for this paper. 
Prior research on the 'left behind' has almost exclusively featured the family as the key source of support and wellbeing. Theoretical insights into the configuration of social support networks suggest, however, that people can rely on multiple sources of support, usually subsumed under the categories of kin, non-kin and professionals (Litwak and Szelenyi 1969; Messeri, Silverstein and Litwak 1993). According to the task-specific model, kin ties are a primary source of support that tends to provide all types of help, especially those requiring long-term commitment. Non-kin ties are most often preferred for emotional support and in case of emergencies, whereas professional help is opted for when the need is for more demanding (physical) care. There might, however, exist an overlap between the support sources and the types of help they provide: when the primary providers are not available, lower-placed ties, that are still able to perform the required task, are likely to step in (Litwak 1985; Messeri, Silverstein and Litwak 1993).

Adopting this support system framework, in this article we first examine older Poles' support patterns, taking into account their living arrangements. Then, we test the premise that when their children are not around, non-kin ties - that is friends, neighbours and others who do not belong to one's family - will become a more important source of support. Using data from the Polish Generations and Gender Survey, we investigate the extent to which increasing geographic distance between parents and their closest child triggers the receipt of practical and emotional support from at least one non-kin tie; at the same time, we account for older adults' family structure, living arrangements and socio-economic status. Our novel achievement in this paper is hence to highlight the relevance of non-kin ties in mechanisms of support in migratory contexts; we are amongst the first to do this.

\section{The case of Poland}

In the transition to the new market economy, the demographic situation in the Central and Eastern European countries changed, in some respects for the worse. Currently, compared with the rest of Europe, this region is characterised by lower fertility, and higher levels of emigration and population ageing (Eurostat 2013). During the communist era, internal and international migration were strictly regulated; leaving the country was not a matter of personal choice. The shift to a market economy brought the closure and downsizing of many former state-run enterprises, resulting in high rates of unemployment and pressures for emigration, which assumed a mass scale after Poland joined the EU in 2004. According to 
the 2011 Polish census, about 2 million Poles lived abroad for at least three months, including about 1.5 million for longer than 12 months (Goździak 2014). Amongst the top destination countries of Poles in Europe are the United Kingdom (UK), Germany, the Netherlands and Ireland (Fihel, Kaczmarczyk and Stefanska 2012). ${ }^{1}$ These statistics suggest that the number of Polish families whose members are separated by a long distance has substantially increased in the past decade or more.

The fall of the Iron Curtain not only brought about considerable modifications in the demographic make-up of the country but also wrought change in its social and institutional context. Older adults 'left behind' in Poland are now embedded in a post-communist welfare regime (Fenger 2007) and a strongly family-based culture (Titkow and Duch 2004). Although Poland has been considered one of the success stories of the transition period (Fenger 2007; Kera and Kessler 2008), the country, like its Eastern European neighbours, has witnessed pronounced reductions in the previously universal socialist welfare system (Deacon 2000). These reductions, in combination with the deterioration of institutions that used to ensure older people's wellbeing (i.e. pensions and the public health system), have led to social problems, including the impoverishment and exclusion of older adults (Botev 2012). According to the latest statistics, in 2014 about 18 per cent of the Polish population aged $6_{5}$ years and more was at risk of poverty or social exclusion (Eurostat 2015).

With regard to Polish family culture, Saraceno and Keck (2010) have argued that Poland falls into a cluster of countries characterised by a high degree of 'familialism by default'. This means that both residential and home-based care for older people are very limited and most of the support provision falls into the family domain. In fact, Titkow and Duch (2004) have argued that the transition to a market economy has strenghtened the institution of the family in Poland, making it an important source of material and psychological support. Social networks and intergenerational relations studies have corroborated this argument, showing that spouses and children, especially daughters, are the most important sources of support (Krzyzowski 2011; Litwin and Stoeckel 2014). Poland is considered a familialistic country not only because of intense actual support provision but also because of strong norms of filial obligation. These reflect expectations regarding the degree to which children should support their parents, and thereby define the social roles of adult children with respect to their ageing parents (Mureşan and Hărăguş 2015). This context of low state support for older adults in combination with high reliance on one's children for support suggests that non-kin ties might gain importance as a source of support when children are not around. 


\section{Prior research on the 'left behind'}

Although increasing in quantity and diversity, prior research on migrants' parents 'left behind' is still limited and almost exclusively focused on family support, as was pointed out in the Introduction. This strand of literature has been partly informed and tinged by an alarmist perspective favoured by mass media and international advocacy organisations showcasing 'elderly orphans' and 'abandoned children' (Cieślińska 2012; Knodel et al. 2010). Academic literature has provided limited support for this alarmist view, suggesting that parents and migrant adult children continue to engage in intensive contact. Moreover, compared with parents without migrant children, parents of both internal and international migrants seem to receive more financial support (Abas et al. 2oog; Cong and Silverstein 2008, 2011; Gedvilaitè-Kordušienè 2015; Guo, Aranda and Silverstein 2009; Knodel et al. 2010; Zimmer, Rada and Stoica 2014). These financial transfers within the migrant family have been shown to increase not only the material resources of the older adults 'left behind' but also their wellbeing and the amount of child care they provide to the offspring of the migrant children (Cong and Silverstein 2008, 2011).

On a less positive note, research has also shown that the parents of migrants receive less practical support than those without migrant children (Cong and Silverstein 2008; Guo, Aranda and Silverstein 2009; Knodel et al. 2010; Zimmer, Rada and Stoica 2014). For the case of China, Guo, Aranda and Silverstein (2009) have furthermore demonstrated that once the positive impact of material transfers is accounted for, parents with migrants seem to have higher levels of depression compared with parents with nonmigrant children. A similar conclusion was drawn by Adhikari, Jampaklay and Chamratrithirong (2011) and Antman (2010), who revealed that older parents with migrant child(ren) are more likely to have symptoms of poor mental and physical health. Hence, financial transfers, mainly migrant remittances, seem to have a positive effect on parents' material wellbeing but there is a trade-off with emotional wellbeing and the lack of 'hands-on' care. This trade-off has been amply illustrated by qualitative research in Albania (King and Vullnetari 2006; King et al. 2014) which has shown that older adults experience feelings of detachment, loss and grief regarding the absence of their children. Older parents find it difficult to adjust to simply not having their children (and grandchildren) 'around' and to be able to be in direct touch with them 'on demand'. From family sociological research, we know that frequent face-to-face interaction is a prerequisite for emotional closeness and ultimately emotional support (Lawton, Silverstein and Bengtson 1994). Accordingly, it could 
be argued that family members who live at a great geographic distance, as compared with those who are in close proximity, might be less likely to exchange not only proximity-related types of support, such as practical help, but also non-proximity types of support, such as emotional help.

Within the rubric of being 'left behind', sources of support beyond the family have rarely been examined, and this is where the original thrust of this paper is located. Hitherto, two studies inform us about support patterns involving non-family members. Adhikari, Jampaklay and Chamratrithirong (2011) have demonstrated that older adults who have migrant children are more likely than those without migrant children to seek treatment from health services. Van Der Geest, Mul and Vermeulen (2004) have, furthermore, argued that, in countries like the Netherlands, where publicsector care arrangements exist, it is likely that when older adults become dependent, they will make use of these arrangements. Yet, these latter authors have also shown that in Greece, where public-sector care arrangements are scarce, of low quality and not preferred, hiring a migrant to take care of older adults 'left behind' is regarded as a respectable practice since the migrant's labour is incorporated into the household domain and thus regarded as part of the family-care model. In this context, migration is thus seen as both a cause of and a solution to the shortage of carers for older people 'left behind'. Research on unpaid help by non-kin ties to those 'left behind' is virtually non-existent, however. ${ }^{2}$

\section{Theoretical background}

Although research in the linked fields of care and migration studies has primarily focused on the family, theoretical discussions in the field of social support networks suggest that people can rely on multiple sources of support. According to the task-specific model (Litwak 1985)-one of the most well-known efforts to formulate the principles that govern the configuration of social support networks (Messeri, Silverstein and Litwak 1993) - whether an individual will turn for support to kin, non-kin or professionals depends upon the structural properties of the relationship and the nature of the task which is required. Kin ties are biological or legal and therefore best suited to fulfil tasks that entail long-term commitment, such as care. The spouse and co-resident children can additionally function in task areas such as immediate practical help, since they share proximity and daily contact. The spouse is also suited to provide emotional support, as the marital dyad is likely to share similarity in interests and values. Neighbours are, by definition, in close proximity and can best handle time-urgent services, whereas friends share interests and affinity and are 
best suited to fulfil tasks related to emotional support, such as providing advice and mutual confiding. Finally, according to the task-specific model, a person will likely turn to a professional when the task requirements exceed the resources (i.e. time and knowledge) of the informal sources of support. This is most often the case when it comes to the more demanding aspects of physical care (Litwak 1985; Litwak and Szelenyi 1969; Messeri, Silverstein and Litwak 1993).

Applying this support system framework to Poland, where a strong family culture prevails, we can expect that both the practical and emotional support networks of older adults will be predominantly kin focused, especially amongst those whose spouse and child(ren) are in close proximity (Hypothesis 1). Yet, given the taskspecificity of the model, we can also assume that this will be more so for practical than for emotional support. In other words, we can expect that older adults in Poland will be more likely to rely on non-kin ties for emotional than for practical support (Hypothesis 1.1). Since professionals are not a primary source of practical and emotional help, and state support in Poland is generally low, we suggest that the role of professionals in older adults' social support networks will be negligible (Hypothesis 1.2).

The task-specific model follows the idea of specialisation, but principles of substitution are also applicable. The task-specific substitution principle is relatively simple: the group that best substitutes for an absent optimal source of support is the one whose structure most closely matches the tasks of the other (Litwak 1985; Messeri, Silverstein and Litwak 1993). In the context of the current research, this means that when children are not around, neighbours, who are by definition close by, will likely become a more important source of practical support, whereas friends, who share similarity in values and interests, will likely become a more important source of emotional support. Regrettably, our data source does not allow for distinguishing between friends and neighbours. We therefore formulate a general hypothesis suggesting that there will be a positive relationship between increasing geographic distance between parents and their closest child and the likelihood that parents will receive practical and emotional support from at least one non-kin tie (Hypothesis 2). Given that children are more likely to be a primary source of practical than emotional support, and that practical support is proximity-related whereas emotional support is not, we also expect that the association between increasing geographic distance between parents and their closest child and practical support from non-kin will be stronger than the association between distance and emotional support (Hypothesis 2.1).

Here, it is important to note that, in order to best understand the role of distance between parents and their closest child in relation to the receipt of support from at least one non-kin tie, it is essential to take into account whether older adults have a spouse (in the household). This is because, 
as suggested by the task-specific model, spouses are typically a primary source of both practical and emotional support (Litwak 1985; Messeri, Silverstein and Litwak 1993). Furthermore, since the demographic and socio-economic background of the parent is likely to be associated with the location of his/her closest child as well as the likelihood of receiving non-kin support, in this research we additionally account for the age and gender of the respondent, whether he/she has more than one child, as well as his/her education, occupation and area of residence.

\section{Analytical approach}

In order to test the above-specified hypotheses, we employ data from the first wave (2010-2011) of the Generations and Gender Survey (GGS; see http://www.ggp-i.org/). The GGS is a nationally representative survey conducted in 19 countries, including Poland. The survey aims to improve our understanding of the family and spans people in the age range 18-79 years. Although designed as a family-pertinent survey, the social network approach of the GGS ensures sufficient information on actual support provision from sources beyond the family, including non-kin ties and professionals. It is important to note, however, that the delineation of networks in the GGS is a combination of 'exchange' and 'role-relation' methods (for more details, see Broese van Groenou and van Tilburg 2007), but unique identifying information (i.e. a name) is collected only in the rolerelation method. This means that the exchange network and role-relation network can only partly be matched and hence limited information is available on the characteristics (i.e. emotional closeness and frequency of contact) of the various members of the exchange network. Despite this limitation, GGS does provide information on the geographical distance between parents and their children, respondents' family structure, living arrangements and their socio-economic background (Dykstra et al. 2016), thereby enabling us to meet our main research aim.

The original sample size of the Polish GGS is about 20,000 people. However, since we are interested in older adults, we selected only those 6,359 respondents aged 60 years or more.

\section{Practical and emotional support networks}

We derive information on practical support from two questions. The first tackles the degree to which the respondent received household help (i.e. cleaning, cooking, shopping, doing repairs and paying bills) from his/her spouse. The second question addresses up to five other network members 
from whom the respondent received regular help with household tasks. Information on emotional support was derived from a question which enquires into whether, over the last 12 months, the respondent has talked to anyone about his/her personal experiences and feelings. The respondents could again name up to five helpers. These in turn could be identified as being a spouse, parents (in-law), children, grandchildren, siblings (kin); friends, acquaintances, neighbours and colleagues (non-kin); and an organisation or a company (professionals).

In order to best understand older adults' support patterns, we used these questions to construct a number of support network variables. We began this procedure by selecting only those survey respondents who received practical and emotional support from at least one person. For practical support, this selection reduced the sample size to 1,029 people, and for emotional support to 3,545 people. As a second step, we created a continuous variable indicating the total number of ties that were named (network size). 3 Given our focus on non-kin ties, as a third step we created a dichotomous variable indicating whether at least one of the five possible helpers was a non-kin tie. 4 Finally, we constructed three dichotomous variables indicating whether the respondents' network is only family, non-kin or professionally based. Employing these variables, we descriptively examine whether the size and composition of both practical and emotional support networks differ for older adults with different living arrangements.

\section{Distance between parents and children}

Employing information about the length of time it takes the older parent to travel to his/her adult child(ren), we constructed a categorical variable indicating how many hours away is the closest child.5 We constructed five categories: (a) the closest child is in the parental household; (b) the closest child is outside the parental home and at a distance of maximum one hour; (c) the closest child is between one and two hours; (d) the closest child is between three and eight hours; (e) the closest child is nine hours away or more. We constructed the variable in such a way that those older adults who fall in the last category (nine or more hours), for example, have no other children living closer than nine hours away, even if they have more than one child.

\section{Living arrangements and control variables}

Given the focal role of the spouse as a source of practical and emotional support, we examine the living configurations of older adults in Poland. We constructed a categorical variable indicating whether (a) the 
respondent has a spouse who is in the household; (b) the respondent has a spouse who is not in the household; or (c) the respondent has no spouse (never married, divorced or widowed).

We furthermore control for respondents' socio-economic and demographic background since we expect that these characteristics will be associated with both the dependent and the key independent variables. The exact characteristics which we control for are: whether the respondent has more than one child (a dichotomous variable, coded 1 for yes), age (a continuous variable), sex (a dichotomous variable, coded 1 for male), educational level (a variable measured on a scale from o, pre-primary education, to 7, high-level academic education), employment (a categorical variable indicating whether the respondent is employed, unemployed, retired or in some other condition such as sick leave or in training) and area of residence (a dichotomous variable coded 1 for urban).

\section{Association between geographic distance and support from at least one non-kin tie}

Employing the variable indicating whether or not older adults have at least one non-kin tie in their support networks and the above-described independent variables, we conduct logistic regression models to examine the relationship between distance separating parents from their closest child and the likelihood that a person will receive practical and emotional support from at least one non-kin tie. We model separately the likelihood for each type of support. We begin the analyses by including the control variables in the model (Model 1). Subsequently, we include the key independent variable: distance between parents and their closest child (Model 2; reference category is the closest child in the parental household). As we add the distance variable, we examine changes in the explained variance or the degree to which distance explains the difference between those with and without at least one non-kin tie in their support networks.

Tables 4 and 5 (which are presented and discussed later in the paper) give the results of the logistic regression models. All coefficients represent how a change in the independent variable is associated with a change in the probability of having at least one non-kin tie in the practical and emotional support network. The coefficients are presented as odds ratios, meaning that coefficients greater than 1 signify a positive association and those below 1 a negative association. Since the odds ratios are somewhat uninformative when it comes to understanding the degree to which non-kin ties provide support and difficult to interpret when it comes to substantive effects (Mood 2010), in Figures 1 and 2 we additionally present the predicted probabilities for receiving support from at least one non-kin over 
Non-kin ties as a source of support in Poland 1265

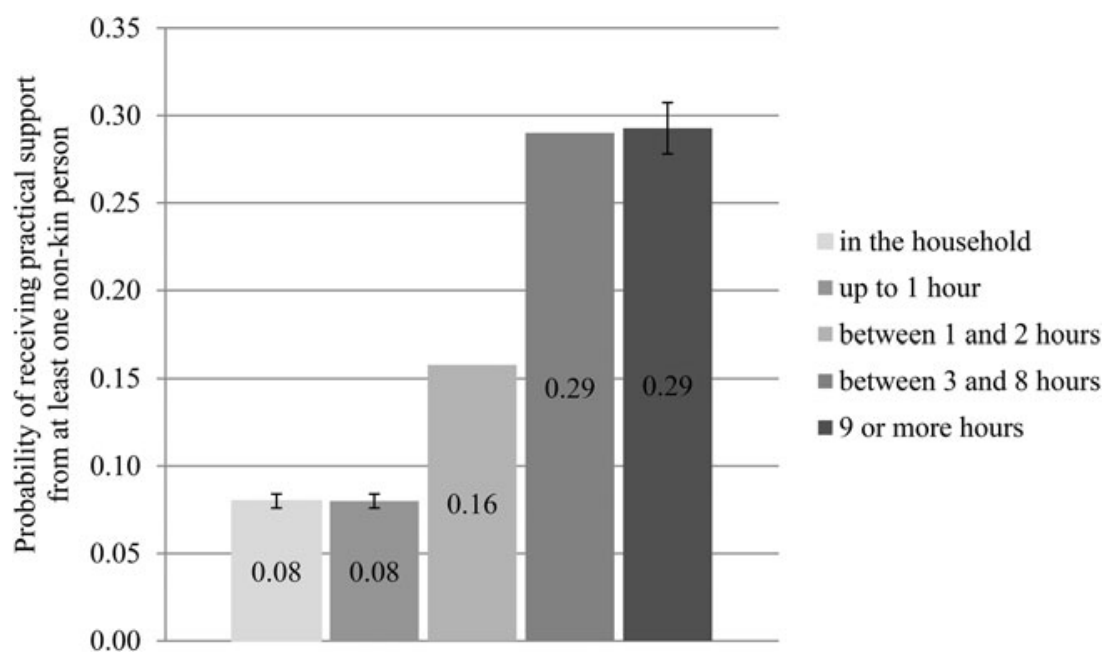

Figure 1. Predicted probabilities of receiving practical help from at least one non-kin tie over proximity of closest child in hours.

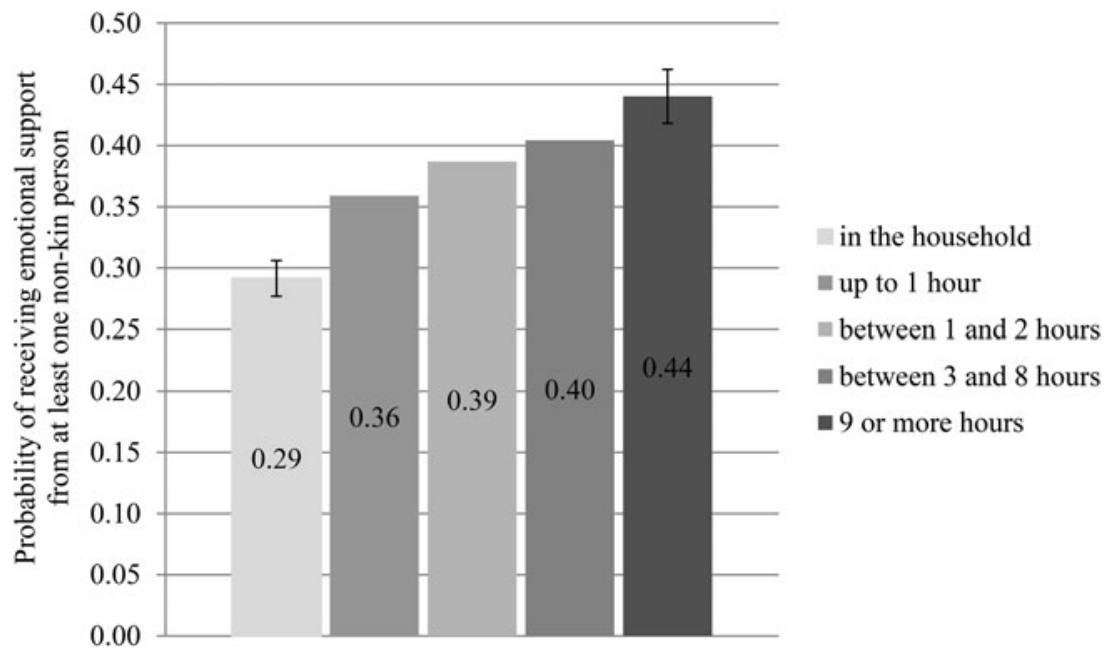

Figure 2. Predicted probabilities of receiving emotional help from at least one non-kin tie over proximity of closest child in hours.

each of the possible categories regarding the location of the closest child. The predicted probabilities hold all other covariates constant at their mean, meaning that these results can be interpreted as the likelihood of non-kin support for a person who is average with regard to the characteristics included in the model. 


\section{Results}

\section{Sample description}

As can be seen in Table 1 , the majority $(53.1 \%)$ of older adults in Poland have their closest child outside the parental household but within a distance of one hour. Just over a quarter $(26.4 \%)$ have their closest child in the parental household, followed by those who have their closest child between one and two hours away (12.5\%). Amongst those with (very) distant children, 5.2 per cent reported their closest child between three and eight hours, and only 2.8 per cent had their closest child more than nine hours away.

Table 2 provides information as to what percentage of older adults in Poland fall into each of the living arrangement configurations given the location of their closest child. The data suggest that the most common living arrangement in Poland includes a spouse living in the respondent's household and a non-resident child at a distance of maximum one hour. As to those 'left behind' by migration, findings show that only 2 per cent of the older adults who have a spouse in the household have their closest child nine or more hours away. Moreover, around 2 per cent have a spouse who is not living in the same household as the respondent, and about 44 per cent have no spouse. From the latter group, about 4 per cent have their closest child more than nine hours away, whereas from those with a non-resident spouse around 9 per cent have no closer child than nine hours away.

Finally, as can be seen in Table 1, about 70 per cent of the respondents reported having more than one child and about 40 per cent are fathers. The mean age is 68.3 years; the majority of respondents are retired $(83 \%)$ and urban residents $(68 \%)$. With regard to education, $5^{1}$ per cent of the sample reported upper secondary education, followed by those at the lower end - primary education $(30 \%)$, and then those at the higher end - first-level tertiary education $(12 \%)$.

\section{Support patterns amongst older adults in Poland}

Tables 3 and 4 provide information on the proportion of older adults who did not receive support, as well as the size and composition of the practical and emotional support networks of those who did receive support. In presenting these data, we distinguish between those who have no spouse and no nearby children (either because they are childless, or their nearest child lives nine or more hours away - hence they have been 'left behind' by migration), and those who have a spouse and the closest child lives at a distance of maximum one hour (the most common living arrangement in the data-set). Here, it is important to note that we rely on a very small 
T A B L 1 . Description of sample by practical and emotional support networks with and without at least one non-kin tie

\begin{tabular}{|c|c|c|c|c|c|}
\hline & \multirow[b]{3}{*}{ Sample average } & \multicolumn{2}{|c|}{ Practical support } & \multicolumn{2}{|c|}{ Emotional support } \\
\hline & & \multicolumn{2}{|c|}{ Support network has: } & \multicolumn{2}{|c|}{ Support network has: } \\
\hline & & At least one non-kin tie & No non-kin ties & At least one non-kin tie & No non-kin ties \\
\hline & & & Percentages $(N)$ & & \\
\hline Child in the household ${ }^{1}$ & $26.4(1,417)$ & $9.1(10)$ & $12.7(96)$ & $19 \cdot 7(218)$ & $28.0\left(54^{6}\right)$ \\
\hline Child within 1 hour ${ }^{1}$ & $53.1(2,847)$ & $57 \cdot 3(63)$ & $73 \cdot 4(555)$ & $55 \cdot 3(612)$ & $53.9\left(1,05^{1}\right)$ \\
\hline Child between 1 and 2 hours ${ }^{1}$ & $12.5(670)$ & $16.4(18)$ & $9 \cdot 7(73)$ & $13.9(154)$ & $11.1(217)$ \\
\hline Child between 3 and 8 hours $^{1}$ & $5.2(281)$ & $12.7(14)$ & $3.0(23)$ & $7.0(77)$ & $4.8(93)$ \\
\hline Child $9+$ hours or abroad ${ }^{1}$ & $2.8\left(15^{1)}\right.$ & $4 \cdot 5(5)$ & $1.2(9)$ & $4.1(45)$ & $2.2(43)$ \\
\hline Living with spouse ${ }^{1}$ & $54 \cdot 7(3,478)$ & $20.3(29)$ & $33.9(300)$ & $3^{8.7}\left(5^{22}\right)$ & $65.9(1,447)$ \\
\hline Living alone, non-resident spouse ${ }^{1}$ & $1.7\left(\begin{array}{lll}1 & 1 & 1\end{array}\right)$ & $2.8(4)$ & $2.4(21)$ & $2.4(32)$ & $1.5(34)$ \\
\hline Living alone, no spouse ${ }^{1}$ & $43.6(2,770)$ & $76.9(110)$ & $63.8\left(5^{6} 5\right)$ & $59.0(796)$ & $32.5(714)$ \\
\hline Two or more children ${ }^{2}$ & $68.9(4,380)$ & $5^{2.4}(75)$ & $74 \cdot 3\left(65^{8}\right)$ & $62.2(840)$ & $76.6(1,681)$ \\
\hline Mean age of respondent $(\mathrm{SD})^{3}$ & $68.3(5.8)$ & $71.5(5 \cdot 7)$ & $71.1(5.8)$ & $68.4(5.7)$ & $68.2(5.8)$ \\
\hline Male & $3^{8.7}(2,460)$ & $24.0\left(\begin{array}{lll}2 & 1 & 3\end{array}\right)$ & $31.0(43)$ & $26.3(355)$ & $40.4(886)$ \\
\hline Employed & $5.6(353)$ & o (o) & $1.5(13)$ & $5.6(75)$ & $6.0(131)$ \\
\hline Unemployed & $7 \cdot 3(463)$ & $9.1(13)$ & $8.1(72)$ & $5.9(80)$ & $7 \cdot 5\left(16_{5}\right)$ \\
\hline Retired & $83.0(5,278)$ & $84.6\left(\begin{array}{lll}1 & 2 & 1\end{array}\right)$ & $83 \cdot 3\left(73^{8}\right)$ & $84.0(1,134)$ & $82.6(1,812)$ \\
\hline Other activity & $4.2(265)$ & $6.3(9)$ & $7.1(63)$ & $4.5(61)$ & $4.0(87)$ \\
\hline Mean level of education $(\mathrm{SD})^{4}$ & $2.6(1.4)$ & $2.5(1.5)$ & $2.3(1.4)$ & $2.9(1.4)$ & $2.6(1.3)$ \\
\hline Urban residence & $68.1(4,329)$ & $69.9(100)$ & $64.9(575)$ & $77.0(1,040)$ & $65.8(1,445)$ \\
\hline
\end{tabular}

Notes: SD: standard deviation. 1. The variables measuring distance between parents and their closest child as well as living arrangements are categorical but for the sake of clarity they are presented as dummy variables. 2 . There were 717 respondents $(11.3 \%)$ who did not have any children and $1,262(19.8 \%)$ who reported having one child. 3 . The age range of the sample is 6o-81. 4. Education was measured on a scale from o (pre-primary education) to 7 (high-level academic education).

Source: Polish Generations and Gender Survey (respondents aged 6o+). 
T A B LE 2. Description of living arrangements for those who have children

\begin{tabular}{lcccccr}
\hline & $\begin{array}{c}\text { Child in the } \\
\text { household }\end{array}$ & $\begin{array}{c}\text { Child } \\
\text { within } \\
1 \text { hour }\end{array}$ & $\begin{array}{c}\text { Child } \\
\text { between 1 } \\
\text { and 2 hours }\end{array}$ & $\begin{array}{c}\text { Child } \\
\text { between } 3 \text { and } 8 \text { hours }\end{array}$ & $\begin{array}{c}\text { Child } 9^{+} \\
\text {hours or } \\
\text { abroad }\end{array}$ & $\begin{array}{c}\text { Total } \\
\text { N }\end{array}$ \\
\hline & & \multicolumn{5}{c}{ Percentages } \\
$\begin{array}{l}\text { Spouse in the household } \\
\text { Non-resident spouse }\end{array}$ & 27.2 & 53.6 & 12.1 & 4.8 & 2.2 & 3,128 \\
No spouse & 11.7 & $5^{1.1}$ & 22.3 & 6.4 & 8.5 & 94 \\
& 25.8 & $5^{2.3}$ & 12.5 & 5.8 & 3.5 & 2,144 \\
\hline
\end{tabular}

Notes: Eight per cent $\left(\mathrm{N}=5^{\circ} \mathrm{O}\right)$ have no partner and no children. Chi-squared test shows significant differences but note that we violate the test assumption of at least five expected counts per cell.

Source: Polish Generations and Gender Survey (respondents aged 6o+).

number of people who fall in the category 'no spouse and nearest child lives nine or more hours away', and therefore the descriptive findings in that regard should be treated with caution. However, we believe it is important to keep these categories separated because our analyses reveal fairly different support system configurations between those who have never had children and those who have children at a large distance, allowing us to begin refining our knowledge on those left behind by migration in Poland.

The findings reveal that 84 per cent of older adults in Poland did not receive practical support from anyone. This proportion is almost twice those who did not receive emotional support (44\%). Moreover, compared with the group of older adults with a spouse and a nearby child (within one hour), we observe a significantly higher share of people with distant children, who did not receive practical help, but this difference is not large: 88 versus $9^{1}$ per cent, respectively (Table 3 ). These group differences are somewhat larger for emotional support, where those with a distant child or no children have a 16 per cent higher observed probability of not receiving support than those with a proximate child (Table 4 ).

Regarding the size of older adults' support networks, the findings suggest that emotional networks are in general larger, with an average size of 2.0 supportive ties, compared to 1.6 ties for practical support. The networks' size differs across different household configurations but not by much: for practical support, those without children have the smallest (1.3 ties) whereas those with a proximate child have the largest ( 1.6 ties) networks. For emotional support, those with a distant child have the smallest (1.6 ties) and those with a proximate child have the largest (2.0 ties) networks.

Next, with regard to the composition of the networks or the degree to which older adults rely on different sources of support, we find, as suggested by Hypothesis 1, that both practical and emotional support networks in Poland are predominantly family focused. Of those who received support, 
T A B LE 3. Practical support networks by living arrangements

\begin{tabular}{|c|c|c|c|c|}
\hline & Sample & $\begin{array}{l}\text { No spouse, } \\
\text { no children }\end{array}$ & $\begin{array}{l}\text { No spouse, } \\
\text { closest child } \\
9^{+} \text {hours }\end{array}$ & $\begin{array}{l}\text { Spouse, closest } \\
\text { child within } \\
1 \text { hour }\end{array}$ \\
\hline No support $(\%)^{*}$ & 83.8 & 80.9 & 90.5 & 87.5 \\
\hline $\begin{array}{l}\text { Mean number of ties in } \\
\text { support network (SD) }\end{array}$ & $1.55(0.8)$ & $1.33(0.7)$ & $1.43(0.5)$ & $1.60(0.9)$ \\
\hline $\begin{array}{l}\text { Support network with at } \\
\text { least one non-kin tie } \\
(\%):{ }^{1 *}\end{array}$ & $13.9^{2}$ & 20.6 & 71.4 & $5 \cdot 7$ \\
\hline $\begin{array}{l}\text { Non-kin ties-only support } \\
\text { network }(\%)^{1 *}\end{array}$ & 7 & $15 \cdot 5$ & 28.6 & 2.4 \\
\hline $\begin{array}{l}\text { Support network without } \\
\text { non-kin ties }(\%) \text { : }\end{array}$ & 86.1 & 70.4 & 28.6 & $94 \cdot 3$ \\
\hline $\begin{array}{l}\text { Kin ties-only support } \\
\text { network }(\%)^{1 *}\end{array}$ & $77 \cdot 3$ & $5^{0.5}$ & 28.6 & $8_{5} .6$ \\
\hline $\begin{array}{l}\text { Support from at least one } \\
\text { professional tie }(\%) \text { : }\end{array}$ & 4.0 & $17 \cdot 5$ & 0.0 & 1.0 \\
\hline $\begin{array}{l}\text { Professional ties-only } \\
\text { network }(\%)^{1 *}\end{array}$ & 1.8 & 12.4 & 0.0 & 0.5 \\
\hline $\begin{array}{l}\text { Total number of people } \\
\text { who received support }\end{array}$ & 1,029 & 97 & 7 & 209 \\
\hline Total N & 6,359 & 507 & 74 & 1,677 \\
\hline
\end{tabular}

Notes: SD: standard deviation. 1. Test of significance is performed but note that we violate the test assumption of at least five expected counts per cell. 2. Of all people who have non-kin ties in their practical support network, 97.2 per cent have only one non-kin tie.

Source. Polish Generations and Gender Survey (respondents aged 6o+).

Significance. *Chi-squared test reveals statistically significant differences between the categories 'no spouse and no children', 'no spouse and closest child $9+$ hours' and 'spouse and closest child within 1 hour'.

77 per cent reported that they relied exclusively on kin for practical help, compared with 60 per cent who relied exclusively on kin for emotional help. Yet, the degree to which older adults rely only on family varies greatly across living arrangements, with those with distant children - and hence effectively 'left behind' by migration - being least likely to have kin-only networks (for both practical and emotional help, $28.6 \%$ have kin-only networks). An interesting finding worth noting here is also that, unlike those with distant children, those older adults with no spouse and no children are still most likely to rely on kin ties only $(51 \%)$ for practical support. Compared with all other living arrangements, childless older adults in Poland are also most likely to rely either exclusively, or on at least one, professional for practical help (12 and 18\%, respectively). For emotional support, however, like those with a distant child, childless older adults are most likely to rely on non-kin ties.

With regard to reliance on non-kin ties, as suggested by Hypothesis 1.1, the findings show that older adults in Poland are more likely to rely on 
T А В L E 4. Emotional support networks by living arrangements

\begin{tabular}{|c|c|c|c|c|}
\hline & Sample & $\begin{array}{l}\text { No spouse, } \\
\text { no children }\end{array}$ & $\begin{array}{l}\text { No spouse, } \\
\text { closest child } \\
9^{+} \text {hours }\end{array}$ & $\begin{array}{l}\text { Spouse, closest } \\
\text { child within } \\
\text { 1 hour }\end{array}$ \\
\hline No support $(\%)^{*}$ & $44 \cdot 3$ & 57.0 & $5^{6.8}$ & $4^{1.1}$ \\
\hline $\begin{array}{l}\text { Mean number of ties in } \\
\text { support network }(\mathrm{SD})^{1} *\end{array}$ & $1.95(1.1)$ & $1.68(0.9)$ & $1.62(0.8)$ & $2.0(1.1)$ \\
\hline $\begin{array}{l}\text { Support network with at } \\
\text { least one non-kin tie:* }\end{array}$ & $3^{8.1^{2}}$ & 70.6 & 71.4 & 26.6 \\
\hline $\begin{array}{l}\text { Non-kin ties-only support } \\
\text { network }(\%)^{1 *}\end{array}$ & $14 \cdot 3$ & $3^{8.1}$ & $4^{2 \cdot 9}$ & 8.3 \\
\hline $\begin{array}{l}\text { Support network without } \\
\text { non-kin ties }(\%) \text { : }\end{array}$ & 61.9 & $29 \cdot 4$ & 28.6 & $73 \cdot 4$ \\
\hline $\begin{array}{l}\text { Kin ties-only support } \\
\text { network }(\%)^{1 *}\end{array}$ & 60.1 & $23 \cdot 9$ & 28.6 & 72.2 \\
\hline $\begin{array}{l}\text { Support from at least one } \\
\text { professional tie }(\%) \text { : }\end{array}$ & 1.1 & $3 \cdot 7$ & $2 \cdot 4$ & 0.4 \\
\hline $\begin{array}{l}\text { Professional ties-only } \\
\text { network }(\%)^{1 *}\end{array}$ & 0.5 & 2.8 & 0.0 & 0.1 \\
\hline $\begin{array}{l}\text { Total number of people } \\
\text { who received support }\end{array}$ & 3,545 & 218 & $4^{2}$ & $9^{8} 7$ \\
\hline Total N & 6,359 & 507 & 74 & 1,677 \\
\hline
\end{tabular}

Notes: SD: standard deviation. 1 . Test of significance is performed but note that we violate the test assumption of at least five expected counts per cell. 2. Of all people who have non-kin ties in their emotional support network, 76.8 per cent have only one non-kin tie.

Source: Polish Generations and Gender Survey (respondents aged 6o+).

Significance. *Chi-squared test reveals statistically significant differences between the categories 'no spouse and no children', 'no spouse and closest child $9^{+}$hours' and 'spouse and closest child within 1 hour'.

friends, neighbours and other non-relatives for emotional than for practical help. As can be seen in Tables 3 and $4,3^{8}$ per cent of all respondents reported at least one non-kin tie in their emotional support network, compared to 14 per cent who have at least one non-kin tie in their practical support network. The same conclusion can be drawn if we turn to exclusive reliance on non-relatives: 14 per cent reported having only non-kin ties as a source of emotional help, compared with 7 per cent for practical help. As expected, we also see that the role of non-kin ties becomes more important when children are not around: 71 per cent of the respondents with distant children have at least one non-kin person in their practical support network, compared to 6 per cent for those with proximate children. This difference exists also for emotional support but it is less extreme, 71 versus 27 per cent. In the next sub-section, we discuss in more detail the association between distance between parents and their closest child and support from at least one non-kin person.

Finally, as suggested by Hypothesis 1.2, professionals play a negligible role in older adults' support networks in Poland, with the notable exception of 
T A B LE 5. Logistic regression results for practical help from at least one non-kin tie

\begin{tabular}{lrr}
\hline & Model 1 & \multicolumn{1}{c}{ Model 2} \\
\hline & \multicolumn{1}{c}{ Odds ratios (standard error) } \\
Proximity of children in hours (Ref. Child in the household) & $0.93(0.35)$ \\
Child within 1 hour & & $2.14(0.95)$ \\
Child between 1 and 2 hours & & $4.65^{* *}(2.33)$ \\
Child between 3 and 8 hours & & $4.72^{*}(3.26)$ \\
Child 9+ hours or abroad & & $1.19(0.85)$ \\
Living arrangement (Ref. Living with spouse) & $1.55(1.04)$ & $3.19^{* * *}(0.91)$ \\
$\quad$ Living alone, non-resident spouse & $3.07^{* * *}(0.86)$ & $0.47^{* *}(0.11)$ \\
$\quad$ Living alone, no spouse & $0.42^{* * *}(0.10)$ & $0.98(0.02)$ \\
Two or more children & $0.98(0.02)$ & $2.54^{* * *}(0.65)$ \\
Age of respondent & $2.27^{* * *}(0.57)$ & - \\
Male & - & $0.79(0.34)$ \\
Employed & $0.78(0.33)$ & $1.06(0.44)$ \\
Unemployed & $1.01(0.41)$ & $1.06(0.09)$ \\
Other activity & $1.11(0.09)$ & $0.92(0.23)$ \\
Education & $0.93(0.23)$ & $0.28(0.43)$ \\
Urban residence & $0.34(0.49)$ & 864 \\
Constant & 864 & 10.6 \\
N observations & 6.9 & -294.5 \\
Nagelkerke $R^{2}(\%)$ & -306.6 & \\
Log-likelihood & &
\end{tabular}

Notes: There are no people who are in employment and received practical support from at least one non-kin tie. Ref.: reference category.

Significance levels: $* p \leqslant 0.05, * * p \leqslant 0.01, * * * p \leqslant 0.001$.

the above-mentioned childless people. On average, 4 per cent of older adults in Poland reported having at least one professional in their practical support network, and only 1 per cent reported at least one professional in their emotional support network.

\section{Association between distance and receiving support from at least one non-kin tie}

We turn now to Tables 5 and 6 and Figures 1 and 2 to document and analyse the association between distance between parents and their closest child and the receipt of practical and emotional support from at least one neighbour, friend or another non-relative. We first examine Model 1 - the control variables-only model - which suggests that a strong positive relationship exists between living alone and/or not having a spouse, and the likelihood of receiving practical support from at least one non-kin person. Compared with mothers, fathers are also more likely to rely on a non-kin tie, whereas having more than one child produces a negative association with non-kin practical support. For emotional support, we find that both 
T А в L E 6. Logistic regression results for emotional support from at least one non-kin tie

\begin{tabular}{|c|c|c|}
\hline & Model 1 & Model 2 \\
\hline & \multicolumn{2}{|c|}{ Odds ratios (standard error) } \\
\hline \multicolumn{3}{|c|}{ Proximity of children in hours (Ref. Child in the household) } \\
\hline Child within 1 hour & & $1.36^{* *}(0.14)$ \\
\hline Child between 1 and 2 hours & & $1.53 * *(0.22)$ \\
\hline Child between 3 and 8 hours & & $1.65^{* *}(0.30)$ \\
\hline Child $9+$ hours or abroad & & $1.91^{* *}\left(0.4^{6}\right)$ \\
\hline \multicolumn{3}{|c|}{ Living arrangement (Ref. Living with spouse): } \\
\hline Living alone, non-resident spouse & $2.31 * *(0.65)$ & $2.17 * *(0.62)$ \\
\hline Living alone, no spouse & $2.71 * * *(0.24)$ & $2.73^{* * *}(0.25)$ \\
\hline Two or more children & $0.74^{* *}(0.07)$ & $0.77^{* *}(0.08)$ \\
\hline Age of respondent & $0.99(0.01)$ & $0.99(0.01)$ \\
\hline Male & $0.73^{* *}(0.07)$ & $0.73^{* *}(0.07)$ \\
\hline Employed & $1.07(0.20)$ & $1.10(0.20)$ \\
\hline Unemployed & $0.96(0.16)$ & $0.98(0.16)$ \\
\hline Other activity & $0.70(0.14)$ & $0.70(0.14)$ \\
\hline Education & $1.13 * * *(0.04)$ & $1.12 * * *(0.04)$ \\
\hline Urban residence & $1.49 * * *(0.14)$ & $1.41 * * *(0.13)$ \\
\hline Constant & $0.54(0.28)$ & $0.53(0.28)$ \\
\hline $\mathrm{N}$ observations & $3,05^{\circ}$ & $3,05^{\mathrm{O}}$ \\
\hline Nagelkerke $R^{2}(\%)$ & 6.6 & 7.1 \\
\hline Log-likelihood & $-1,863.8$ & $-1,855 \cdot 3$ \\
\hline
\end{tabular}

Note: Ref.: reference category.

Significance levels: * $p \leqslant 0.05, * * p \leqslant 0.01, * * * p \leqslant 0.001$.

not having a partner, and having a partner who is non-resident in the household, matters. As with practical support, we also find a negative association between having more than one child and non-kin support; but, unlike practical support, fathers are less likely than mothers to receive emotional support from a friend or a neighbour. Finally, although not very strong, there seems to exist a positive relationship between education and area of residence, on the one hand, and non-kin support, on the other. Highly educated older adults in cities are more likely to receive emotional support from at least one non-kin tie. For both types of support, the control variables explain about 7 per cent of the variance.

Model 2 takes into account our key independent variable: distance between parents and their closest child. For practical support, we see that older adults with child(ren) in the parental home (reference category) seem to differ significantly only from those with children between three and eight hours distant, and nine hours or more. In other words, up to three hours, increasing distance between the closest child and the parent does not make the parent more likely to add a non-kin tie to their practical support network. Turning to the marginal effects presented in Figure 1, we 
also see that the magnitude of change is quite high: holding values for all control variables at their mean values, older adults who fall the into the category 'closest child is at a distance of nine hours or more' have on average a 29 per cent chance of receiving practical support from at least one non-kin tie, compared with only a 1 per cent chance for non-kin support amongst those with a proximate child, or an 18 per cent chance for all older adults together. It is interesting to note here that older adults with very distant children, i.e. those likely to be 'left behind' by international migration, differ significantly only from those older adults with a child in the household or at a distance of less than one hour (coefficients are significant at $p=0.03$ and 0.01 , respectively). Finally, adding the distance variable to the model results in about 4 per cent additional explained variance.

For emotional support there is also a positive and significant relationship between the distance separating parents from their closest child and nonkin support, whereby those with a child in the household differ significantly from all other categories. Thus, when it comes to emotional support, nonrelatives are more likely to become part of the support network as soon as the child leaves the parental household. In Figure 2 we see, however, that the magnitude of change in probability is small, and hence older adults' likelihood of receiving emotional support from a friend or a neighbour seems not to be strongly conditioned by the distance between them and their closest child. Holding all other variables at their means, the average predicted probability for non-kin emotional support is $3^{8}$ per cent, whereas the probability for non-kin emotional support amongst those with a co-resident and a distant (nine or more hours away) child is 29 and 44 per cent, respectively. As with practical support, those with a distant child differ significantly only from those with a household child (coefficient is significant at $p=0.01)$. Finally, adding the distance variable in the model results in very little $(0.5 \%)$ additional explained variance. For both types of support, the control variables' coefficients remain virtually unchanged after including the key independent variable of time-based distance in the model.

\section{Conclusions}

Building upon prior research, this paper has argued that large-scale emigration flows of young people and considerable reductions in previously universal welfare systems in Central and Eastern European countries have contributed to create the phenomenon of 'left-behind' older adults. We examined this phenomenon in the case of Poland, a country which has sent very large numbers of emigrants to Western Europe in recent years. 


\section{Nina Conkova and Russell King}

More specifically, the paper enquired into older adults' support patterns given their living arrangements, and tested the premise that, when their children are not around, non-kin ties become a more important source of support. This has been our specific original contribution to what Toyota, Yeoh and Nguyen (2007) have called the 'migration-left behind nexus'.

Research on people 'left behind' by migration tends to be fuelled by concerns about support provision and the wellbeing of older adults (Toyota, Yeoh and Nguyen 2007). Adopting a dyadic perspective, prior studies have corroborated these concerns regarding issues of care and practical support, demonstrating that the parents of migrants tend to receive less 'hands-on' help than those without migrant children (Cong and Silverstein 2008; Guo, Aranda and Silverstein 2009; Knodel et al. 2010; Zimmer, Rada and Stoica 2014). In contrast to these studies, we adopted in this paper a more explicit recipient perspective and found more positive evidence about support provision. We showed that older adults 'left behind' by migration in Poland do receive significantly less support and have smaller support networks than their counterparts with proximate children, but these differences are not large. Future research might be able to bring new insights into the phenomenon of those 'left behind' by migration in Poland by focusing on older adults who did not receive support. An interesting question in that regard pertains to whether older adults did not receive support because they did not need it, or because they did not want to receive it, or because there were no network ties willing or able to provide support. Moreover, unlike this research which is cross-sectional and thus gave no clues as to how the patterns and needs of support for older adults 'left behind' by migration change over time, future research might be able to accumulate new knowledge by adopting a longitudinal perspective. As people grow old, their needs for care and support generally increase. Developing and testing hypotheses about the role of needs in determining support patterns amongst the 'oldest old' might prove informative in understanding the phenomenon of 'left behind'.

Turning to those who received help, i.e. about 20 per cent of our sample for practical support and about 6o per cent for emotional support, our findings suggest that support networks in Poland are comprised primarily of family ties, especially amongst those with a proximate spouse and child (ren). That Poland is a rather familialistic country has been suggested by prior research (Krzyżowski 2011; Litwin and Stoeckel 2014; Titkow and Duch 2004) and is further corroborated by our finding that family remains the most important source of practical support even amongst those older adults who have no spouse and never had children. Previous work on childless people has suggested that these kin ties are likely to be siblings and their children (Albertini and Mencarini 2014; Dykstra 2015). In 
line with prior research in countries with low state support for older adults (Van Der Geest, Mul and Vermeulen 2004), we also demonstrated that the role of professionals in older Poles' support networks is negligible, with the notable exception of childless people.

The degree to which older adults in Poland rely on family support varies greatly across living arrangements and types of support, however. With regard to the latter, we demonstrated that both full and partial reliance on non-kin ties is much more likely for emotional than practical support. With regard to living arrangements, we observed that older adults 'left behind' by migration seem to be more likely to rely on non-kin ties for both practical and emotional support. Hence, by means of descriptive analysis, it can be concluded that, although non-kin ties serve as a source of support less often than kin ties do, they play an important role for those older Poles whose children live far away. This finding bears significant policy relevance, especially in the Polish context, where state support for older adults is limited. Since practical support, including some aspects of demanding personal care, do not fall naturally into the domain of nonkin ties, yet do seem to occur, social policy that enables and supports people to provide help to non-kin (e.g. cash entitlements when helping a neighbour) could prove instrumental in strengthening informal support for older adults.

Consistent with this descriptive analysis, logistic regression analysis revealed that a positive relationship exists between increasing geographic distance between parents and their closest child and the receipt of nonkin support, even when we account for the presence of a spouse and other children. Furthermore, we established that this association differentiates between practical and emotional support. For practical support, results revealed that, up to three hours, increasing geographic distance between parents and their closest child does not make parents more likely to add a non-kin tie to their support network. This is probably because, as suggested by the task-specific model (Litwak 1985; Messeri, Silverstein and Litwak 1993), kin ties are simply better suited to provide help with household tasks. For emotional support, on the other hand, the findings suggested that non-kin ties are more likely to become part of older adults' support networks as soon as the closest child leaves the parental home. This, along with the finding that a spouse's presence in the household significantly decreases the probability of receiving emotional support from at least one non-relative, corroborates the thesis that daily face-to-face contact is a crucial determinant of emotional closeness and ultimately emotional support (Lawton, Silverstein and Bengtson 1994).

Findings for practical and emotional support also differ when it comes to effect sizes and explained variance. Although non-kin ties seem to be 
activated as a source of support at a shorter distance for emotional than for practical help, the overall effect of distance is much stronger when it comes to practical household help. Distance between parents and their closest child seems to explain very little of the difference between those with and those without one non-kin tie in their emotional support network, allowing us to conclude that distance matters much more for practical support. This is in agreement with prior studies which have persistently shown that migration is more detrimental to the receipt of proximity-related types of support than it is for non-proximity types of support (Bordone and De Valk 2013; Ryan et al. 2008, 2009; Wolff, Spielerman and Attias-Donfut 2007).

On a different but related note, the regression results also suggested that older adults with very distant children differ only from those with very proximate children, with this significant difference applicable to both practical and emotional support. This, along with the finding that only about 3 per cent of older Poles have children further than nine hours away, open questions such as could the 'left behind by migration' in Poland be more of a regional than a national phenomenon, and how people 'left behind' by international and those similarly affected by internal migration differ, if at all. Biao $(2007)$, in his study on rural China, suggested that the phenomenon of being 'left behind' can in fact be attributed less to mobility and more to the fundamental problem that many rural communities are economically and socially left behind. As suggested by Zimmer, Rada and Stoica (2014), this also holds true in the former socialist countries of Central and Eastern Europe, where rapid urbanisation and rural depopulation have led to a deterioration in the quality and sustainability of rural life. This has resulted in greater numbers of single older adults, who are marginalised and much more in need of informal support than their urban counterparts. Poland has witnessed spatially different rates of emigration and economic development (Cieślińska 2012) and some qualitative work in the regions which were most affected would prove useful to achieve a more in-depth geographical understanding of the phenomenon of the 'left behind'.

To recap, this contribution sheds new light on the phenomenon of the socalled 'left behind' in Poland by demonstrating that, in contrast with the average older Pole, those 'left behind' by long-distance migration are not necessarily much less likely to receive support; yet their support networks' compositions differ. We also argued that the phenomenon of the 'left behind', at least in terms of support patterns, might be less a matter of distance and more an issue of household and regional context. As a final point, we would like to suggest that future research on the phenomenon of older people 'left behind' by migration could be profitably accomplished through the lens of wellbeing. On the one hand, previous research in the field of migration studies has suggested that older adults with migrant children experience 
feelings of loss and grief from the absence of their children (King and Vullnetari 2006; King et al. 2014). On other hand, prior work in the field of support provision has demonstrated that both practical and emotional nonkin support is positively associated with older adults' wellbeing (Merz and Huxhold 2010). How these opposing effects interact to shape the phenomenon of 'left behind' in Europe remains to be fully explored.

\section{Acknowledgements}

The authors gratefully acknowledge funding from the European Research Council (ERC; Advanced Grant Number 324211, Families in Context). We also thank Alistair Hunter, Maja Djundeva, Tineke Fokkema and the anonymous referees for their valuable comments and suggestions.

\section{NOTES}

1 Labour restrictions on Polish migrants were removed in 2007 in the Netherlands and in 2011 in Germany. Poles have had unrestricted entry to the UK and Ireland (and Sweden) since 2004 (Goździak 2014).

2 To our knowledge, the only study which addressed non-kin ties as an unpaid source of support is Cieślińska (2012). This study focuses, however, on 'left behind' children in Poland. Its findings suggest that, in the rare cases when both parents emigrated, children are cared for by other relatives, friends and neighbours.

3 Although the GGS imposed a limit of five to the number of social relationships a respondent could name, Dykstra et al. (2016) have shown that this restriction does not significantly affect the size of the support networks across the countries included in the data-set. More specifically, these authors demonstrated that only a small percentage of the respondents used all five slots. True, the mean size of the support networks is somewhat larger in the no-cap than in the cap condition, but this difference is minor.

4 We also examined how many of those who reported at least one non-kin tie had in fact only one non-kin tie in their support network. For practical support, this is the case for 97.2 per cent of the respondents, and for emotional support for 76.8 per cent of the respondents. These high proportions vindicate our decision to employ a binary rather than a count variable as a key dependent variable.

5 The measurement of distance can be quantified in three main ways - by linear distance (in kilometres $e t c$.), by time taken to make the trip and by cost. For this exercise (and also because the data-set provided this measure), we use the time travelled as the most practical and realistic metric.

\section{References}

Abas, M.A., Punpuing, S., Jirapramukpitak, T., Guest, P., Tangchonlatip, K., Leese, M. and Prince, M. 2009. Rural-urban migration and depression in ageing family members left behind. British Journal of Psychiatry, 195, 1, 54-6o. 
Adhikari, R., Jampaklay, A. and Chamratrithirong, A. 2011 . Impact of children's migration on health and health care-seeking behavior of elderly left behind. BMC Public Health, 11, 1, 1-8.

Albertini, M. and Mencarini, L. 2014. Childlessness and support networks in later life: new pressures on familistic welfare states? Journal of Family Issues, 35, 3, $33^{1-57}$.

Antman, F. M. 2010. Adult child migration and the health of elderly parents left behind in Mexico. American Economic Review, 10, 2, $205^{-8 .}$

Baldassar, L. 2007 Transnational families and aged care: the mobility of care and the migrancy of ageing. Journal of Ethnic and Migration Studies, 33, 2, 275-97.

Baldassar, L., Baldock, C. V. and Wilding, R. 2007. Families Caring Across Borders: Migration, Ageing and Transnational Caregiving. Palgrave Macmillan, Basingstoke, UK.

Biao, X. 2007. How far are the left-behind left behind? A preliminary study in rural China. Population, Space and Place, 13, 3, 1 79-91.

Black, R., Engbersen, G., Okolski, M. and Pantiru, C. 2010. A Continent Moving West? EU Enlargement and Labour Migration from Central and Eastern Europe. Amsterdam University Press, Amsterdam.

Bordone, V. and De Valk, H. 2013. Intergenerational relationships among migrant families in Europe. Conference paper for the Population Association of America Annual Meeting. Available online at http://medcontent.metapress.com/index/ $\mathrm{A}_{5} \mathrm{RMo}_{3} \mathrm{P}_{4} 87_{42}{ }_{43} \mathrm{~N}$.pdf [Accessed 3 November 2016 ].

Botev, N. 2012. Population ageing in Central and Eastern Europe and its demographic and social context. European Journal of Ageing, 9, 1, 69-79.

Broese van Groenou, M. I. and van Tilburg, T. 2007. Network analysis. In Birren, J. E. (ed.), Encyclopedia of Gerontology. Elsevier, San Diego, California, 242-50.

Cieślińska, B. 2012. The experience of labour emigration in the life of married women: the case of Podlasie, Poland. International Migration, 52, 1, $5^{6-73}$.

Cong, Z. and Silverstein, M. 2008. Intergenerational time-for-money exchanges in rural China: does reciprocity reduce depressive symptoms of older grandparents? Research in Human Development, 5, 1, 6-25.

Cong, Z. and Silverstein, M. 2011 . Intergenerational exchange between parents and migrant and nonmigrant sons in rural China. Journal of Marriage and Family, 73, 1, 93-104.

Deacon, B. 200o. Eastern European welfare states: the impact of the politics of globalization. Journal of European Social Policy, 1o, 2, 146-61.

Dykstra, P.A. 2015. Childless older adults. In Whitbourne, S. K. (ed.), The Encyclopedia of Adulthood and Aging. John Wiley \& Sons, Hoboken, New Jersey, 1-5.

Dykstra, P. A., Bühler, C., Fokkema, T., Petrič, G., Platinovšek, R., Kogovšek, T. and Hlebec, V. 2016. Social network indices in the Generations and Gender Survey. Demographic Research, 34, 35, 995-1036.

Eurostat 2013. Eurostat Regional Yearbook 2013. Publication Office of the European Union, Luxembourg.

Eurostat 2015. Statistics Explained: People at Risk of Poverty or Social Exclusion. Available online at http://ec.europa.eu/eurostat/statistics-explained/index.php/People_ at_risk_of_poverty_or_social_exclusion [Accessed 10 December 2016].

Favell, A. 2008. The new face of East-West migration in Europe. Journal of Ethnic and Migration Studies, 34, 5, 701-16.

Fenger, M. 2007. Welfare regimes in Central and Eastern Europe: incorporating post-communist countries in a welfare regime typology. Contemporary Issues and Ideas in Social Sciences, 3, 2, 1-30. 
Fihel, A., Kaczmarczyk, P. and Stefanska, R. 2012. Recent trends in international migration in Poland. Central and Eastern European Migration Review, 1, 1, 69-9o.

Gedvilaitè-Kordušienè, M. 2015. Norms and care relationships in transnational families: the case of elderly parents left behind in Lithuania. Baltic Journal of European Studies, 5, 2, 90-107.

Goździak, E. M. 2014. Polish migration after the fall of the Iron Curtain. International Migration, 52, 1, 1-3.

Guo, M., Aranda, M. P. and Silverstein, M. 2009. The impact of out-migration on the inter-generational support and psychological wellbeing of older adults in rural China. Ageing EO Society, 29, 7, $1085^{-104}$.

He, C. and Ye, J. 2014. Lonely sunsets: impacts of rural-urban migration on the leftbehind elderly in rural China. Population, Space and Place, 2o, 5, 352-69.

Kera, G. and Kessler, G. 2008. Urban household and family in twentieth century East and South-East Europe. History of the Family, 13, 2, $119^{-2} 5$.

King, R., Cela, E., Fokkema, T. and Vullnetari, J. 2014. The migration and well-being of the zero generation: transgenerational care, grandparenting, and loneliness amongst Albanian older people. Population, Space and Place, 2o, 8, 728-38.

King, R. and Vullnetari, J. 20o6. Orphan pensioners and migrating grandparents: the impact of mass migration on older people in rural Albania. Ageing E Society, 26, $5,78_{3}-816$.

Knodel, J., Kespichayawattana, J., Saengtienchai, C. and Wiwatwanich, S. 2010. How left behind are rural parents of migrant children? Evidence from Thailand. Ageing E Society, 3o, $5,811-41$.

Knodel, J. and Saengtienchai, C. 2007. Rural parents with urban children: social and economic implications of migration for the rural elderly in Thailand. Population, Space and Place, 13, 3, 193-210.

Krzyzowski, L. 2011. In the trap of intergenerational solidarity: family care in Poland's ageing society. Polish Sociological Review, 1, 173, 55-78.

Krzyzowski, L. and Mucha, J. 2014. Transnational caregiving in turbulent times: Polish migrants in Iceland and their elderly parents in Poland. International Sociology, 29, 1, 22-37.

Lawton, L., Silverstein, M. and Bengtson, V. 1994. Affection, social contact, and geographic distance between adult children and their parents. Journal of Marriage and Family, 56, 1, 57-68.

Litwak, E. 1985. Helping the Elderly: The Complementary Roles of Informal Networks and Formal Systems. Guilford Press, New York.

Litwak, E. and Szelenyi, I. 1969. Primary group structures and their functions: kin, neighbors, and friends. American Sociological Review, 34, 4, 465-81.

Litwin, H. and Stoeckel, K. J. 2014. Confidant network types and well-being among older Europeans. The Gerontologist, 54, 5, 762-72.

Merz, E.-M. and Huxhold, O. 2010. Wellbeing depends on social relationship characteristics: comparing different types and providers of support to older adults. Ageing Eo Society, 3o, $5,843-57$.

Messeri, P., Silverstein, M. and Litwak, E. 1993. Choosing optimal support groups: a review. Journal of Health and Social Behaviour, 34, 2, $122-37$.

Mood, C. 2010. Logistic regression: why we cannot do what we think we can do, and what we can do about it. European Sociological Review, 26, 1, 67-82.

Mureşan, C. and Hărăguş, P.-T. 2015. Norms of filial obligation and actual support to parents in Central and Eastern Europe. Romanian Journal of Population Studies, 9, 2, 49-81.

Ryan, L., Sales, R., Tilki, M. and Siara, B. 2008. Social networks, social support and social capital: the experiences of recent Polish migrants in London. Sociology, 42, 4, 672-9o. 
Ryan, L., Sales, R., Tilki, M. and Siara, B. 2009. Family strategies and transnational migration: recent Polish migrants in London. Journal of Ethnic and Migration Studies, 35, 1, 61-77.

Saraceno, C. and Keck, W. 2010. Can we identify intergenerational policy regimes in Europe? European Societies, 1 2, 5, 675-96.

Titkow, A. and Duch, D. 2004. The Polish family: always an institution? In Robila, M. (ed.), Families in Eastern Europe. Elsevier, Amsterdam, 69-85.

Toyota, M., Yeoh, B. S. A. and Nguyen, L. 2007. Bringing the 'left behind' back into view in Asia: a framework for understanding the 'migration-left behind nexus'. Population, Space and Place, 13, 3, 157-61.

Van Der Geest, S., Mul, A. and Vermeulen, H. 2004. Linkages between migration and the care of frail older people: observations from Greece, Ghana and The Netherlands. Ageing $\mathcal{E}^{2}$ Society, 24, 3, 431-50.

Waidler, J., Vanore, M., Gassmann, F. and Siegel, M. 2016. Does it matter where the children are? The wellbeing of elderly people 'left behind' by migrant children in Moldova. Ageing E्ज Society, 36, 1, 1-26.

Wolff, F., Spielerman, S. and Attias-Donfut, C. 2007. Transfers from migrants to their children: evidence that altruism and cultural factors matter. Review of Income and Wealth, 53, 4, 619-44.

Zhou, Y. R. 201 2. Space, time, and self: rethinking aging in the contexts of immigration and transnationalism. Journal of Aging Studies, 26, 3, 232-42.

Zimmer, Z., Rada, C. and Stoica, C. A. 2014. Migration, location and provision of support to old-age parents: the case of Romania. Journal of Population Ageing, 7 , $3,161-84$.

Accepted 5 December 2017 ; first published online I I January 2018

Address for correspondence:

Nina Conkova,

Department of Public Administration and Sociology,

Erasmus University Rotterdam, Burg. Oudlaan 5o,

3o62 PA Rotterdam, The Netherlands

E-mail: conkova@fsw.eur.nl 